\title{
Acute Cortical Lesions in MELAS Syndrome: Anatomic Distribution, Symmetry, and Evolution
}

\author{
(D) K.D. Bhatia, (D) P. Krishnan, (D) H. Kortman, (D). Klostranec, and (D). Krings
}

\begin{abstract}
BACKGROUND AND PURPOSE: Mitochondrial encephalomyopathy with lactic acidosis and stroke-like episodes (MELAS) syndrome is a rare mitochondrial disorder affecting children and young adults. Stroke-like episodes are often associated with acute cortical lesions in the posterior cerebral cortex and are classically described as asymmetric and transient. In this study we assessed the anatomic distribution of acute cortical lesions, the incidence of symmetry, and the temporal evolution of lesions.
\end{abstract}

MATERIALS AND METHODS: This was a retrospective cohort study of patients who had a confirmed genetic diagnosis of a pathogenic variant associated with MELAS and MR imaging performed at our center (2006-2018). Each MR imaging study was assessed for new lesions using T1, T2, FLAIR, DWI, ADC, and SWI. The anatomic location, symmetry, and temporal evolution of lesions were analyzed.

RESULTS: Eight patients with the same pathogenic variant of MELAS (MT-TL1 m.3243A>G) with 31 MR imaging studies were included. Forty-one new lesions were identified in 17 of the studies (5 deep, 36 cortical). Cortical lesions most commonly affected the primary visual cortex, the middle-third of the primary somatosensory cortex, and the primary auditory cortex. Thirty of 36 cortical lesions had acute cortical diffusion restriction, of which 21 developed cortical laminar necrosis on subacute imaging. Six of 11 studies with multiple lesions showed symmetric cortical involvement.

CONCLUSIONS: Acute cortical lesions in MELAS most commonly affect the primary visual, somatosensory, and auditory cortices, all regions of high neuronal density and metabolic demand. The most common pattern of temporal evolution is acute cortical diffusion restriction with subacute cortical laminar necrosis and chronic volume loss. Symmetric involvement is more common than previously described.

ABBREVIATIONS: BA = Brodmann area; MELAS = mitochondrial encephalomyopathy with lactic acidosis and stroke-like episodes

M itochondrial encephalomyopathy with lactic acidosis and stroke-like episodes (MELAS) syndrome is a rare mitochondrial disorder affecting children and young adults. MELAS typically presents between 2 and 40 years of age with stroke-like episodes (classically acute hemiparesis, hemianopia, or cortical blindness), seizures, recurrent headaches, or muscle weakness and can progress with multifocal cerebral atrophy into dementia. ${ }^{1-3}$ MR imaging is helpful in establishing the diagnosis through

Received July 5, 2019; accepted after revision October 2.

From the Division of Neuroradiology (K.D.B., H.K., J.K., T.K.), Joint Department of Medical Imaging, Toronto Western Hospital, Toronto, Ontario, Canada; and Department of Diagnostic Imaging (P.K.), Hospital for Sick Children, Toronto, Ontario, Canada.

Please address correspondence to Kartik Dev Bhatia, MD, Division of Neuroradiology, Level 3, Toronto Western Hospital, 399 Bathurst St, Toronto, M5T 2S8, ON, Canada; e-mail: Kartik.bhatia@uhn.ca

Indicates article with supplemental on-line tables.

http://dx.doi.org/10.3174/ajnr.A6325 demonstration of cortical lesions of varying ages that do not conform to typical vascular distributions. ${ }^{4,5}$

Two established sets of clinical diagnostic criteria exist for the syndrome (Hirano et al, ${ }^{6} 1992$, and Yatsuga et al, ${ }^{1}$ 2012), with the latter taking into account developments in genetic diagnoses (On-line Table 1). While at least 15 different mitochondrial mutations have been associated with MELAS, a single base substitution mutation of adenine for guanine at nucleotide pair 3243 of the mitochondrial DNA molecule (MT-TL1 m.3243A $>$ G pathogenic variant) is present in approximately $80 \%$ of cases. ${ }^{2,7}$ Phenotypic expression of this genotype is variable and dependent on heteroplasmy of mitochondrial DNA, which can influence the age of presentation and disease burden. ${ }^{8,9}$ Elevated lactate and pyruvate levels are often found on blood and CSF analysis, and muscle biopsy typically demonstrates ragged-red fibers and strongly succinate dehydrogenase-reactive vessels. ${ }^{1,2,10}$

Typical MR imaging findings in an acute stroke-like episode of MELAS include gyral swelling, ${ }^{4,5}$ gyriform cortical diffusion restriction (previously thought not to occur in MELAS but 
Table 1: Genetic testing results and clinical presentation

\begin{tabular}{|c|c|c|c|c|c|}
\hline $\begin{array}{l}\text { Patient } \\
\text { No. }\end{array}$ & Sex & $\begin{array}{l}\mathrm{Age}^{\mathrm{a}} \\
(\mathrm{yr})\end{array}$ & $\begin{array}{l}\text { No. of MR Imaging } \\
\text { Studies Available }\end{array}$ & Genetic Testing Results & Clinical Presentation: First Available MR Imaging \\
\hline $1^{\mathrm{b}}$ & Female & 20 & 2 & MT-TL1 m.3243A $>\mathrm{G}$ & $\begin{array}{l}\text { Stroke-like episode } \\
\text { Right facial numbness }\end{array}$ \\
\hline $2^{\mathrm{b}}$ & Female & 27 & 1 & $\begin{array}{l}\text { MT-TL1 m.3243A }>\mathrm{G} \\
\text { Heteroplasmy } 21 \%\end{array}$ & $\begin{array}{l}\text { Asymptomatic } \\
\text { Screening MRI after sibling diagnosed }\end{array}$ \\
\hline 3 & Male & 56 & 1 & MT-TL1 m.3243A $>$ G & $\begin{array}{l}\text { Follow-up study } \\
\text { Childhood diagnosis }\end{array}$ \\
\hline 4 & Female & 23 & 10 & MT-TL1 m.3243A $>$ G & $\begin{array}{l}\text { Stroke-like episode } \\
\text { Right hemiparesthesia followed } 1 \text { week later by } \\
\text { partial status epilepticus }\end{array}$ \\
\hline 5 & Female & 32 & 2 & MT-TL1 m.3243A $>$ G & $\begin{array}{l}\text { Follow-up study } \\
\text { Childhood diagnosis }\end{array}$ \\
\hline 6 & Female & 18 & 8 & MT-TL1 m.3243A $>$ G & $\begin{array}{l}\text { Seizure } \\
\text { Left upper limb paresthesia with secondary } \\
\quad \text { generalization }\end{array}$ \\
\hline 7 & Male & 26 & 6 & MT-TL1 m.3243A $>$ G & $\begin{array}{l}\text { Encephalopathy } \\
\text { Confusion and headaches }\end{array}$ \\
\hline 8 & Female & 40 & 1 & MT-TL1 m.3243A $>\mathrm{G}$ & $\begin{array}{l}\text { Stroke-like episode } \\
\text { Right homonymous hemianopia }\end{array}$ \\
\hline
\end{tabular}

Note:-MT-TL1 m.3243A>G indicates a substitution point mutation of adenine for guanine at nucleotide pair 3243 in the MT-TL1 mitochondrial DNA sequence (associated with $80 \%$ of all MELAS cases).

${ }^{a}$ Age at time of first MR imaging available for review.

bsiblings.

increasingly recognized in early imaging), ${ }^{10-13}$ subcortical white matter T2 FLAIR hyperintensity with elevated ADC values, ${ }^{10,11}$ and elevated parenchymal lactate in both acutely affected and nonaffected brain regions on MR spectroscopy. ${ }^{4,14}$ Lesions frequently spread to the cortex of adjacent gyri with time in a migratory fashion, resulting in large regions of cortical involvement that cross the boundaries of arterial vascular territories, often associated with seizures. ${ }^{10,15,16}$ In the subacute phase, cortical lesions may develop T2 hypointensity ("black toenail sign") and T1 gyriform hyperintensity, in keeping with cortical laminar necrosis. ${ }^{17-19}$ In the chronic stage, gyral infarcts evolve into areas of encephalomalacia, volume loss, and progressive multifocal cerebral and cerebellar atrophy, with associated cognitive decline. ${ }^{3}$ Symmetric basal ganglia calcifications have also been described. ${ }^{20}$

The anatomic distribution of acute lesions is typically in the occipital, parietal, and posterior temporal lobes as well as the cerebellar hemispheres, ${ }^{1,5,20}$ though involvement of the lateral temporal cortex, mesial temporal lobes, and posterior frontal cortex has been described. ${ }^{19,21,22}$ Classic involvement of the pericalcarine visual cortex in the medial occipital lobes is associated with episodes of hemianopia or cortical blindness. ${ }^{1,23}$ Cortical involvement has typically been described as asymmetric $^{4-6,17}$; however, cases with symmetric involvement are increasingly recognized, ${ }^{19,24}$ and the incidence of symmetric involvement is unknown.

In this study, we aimed to assess, in detail, the anatomic distribution of acute cortical lesions in MELAS, the incidence of symmetric involvement, and the temporal evolution of lesions.

\section{MATERIALS AND METHODS}

Ethics approval for this study was granted by the University Health Network Research Ethics Board (approval No. 13-6081). This was a retrospective cohort study of patients meeting the following inclusion criteria: 1) confirmed genetic diagnosis of a pathogenic variant associated with MELAS, and 2) MR imaging performed at our center between 2006 and 2018.

The following data points were collected from the electronic patient records: sex, age in years at the time of first MR imaging at University Health Network, Toronto, clinical presentation for each MR imaging study performed, and results of mitochondrial DNA genetic testing. Imaging was initially assessed by a fellowship-trained diagnostic neuroradiologist (P.K.), and the findings were then confirmed with independent assessment by a fellowship-trained diagnostic and interventional neuroradiologist (K.D.B.). Disagreements were resolved by a senior reviewer (T.K.).

Each available MR imaging study (all performed on the same 3T machine, which has undergone multiple hardware and software upgrades during this 12 -year period) was assessed for new cortical or deep parenchymal lesions, defined as a T2 FLAIR focal hyperintensity affecting the cortex/folia and/or juxtacortical white matter (cortical lesion) or the deep parenchymal structures and not present on the prior study (if available), and excluding cases of spread from contiguous gyri affected on the previous study. Sequence-specific imaging characteristics of each new lesion were assessed on T1, T2, FLAIR, DWI $(b=1000)$, ADC, SWI, MR spectroscopy, and, when available, gadolinium-enhanced T1 imaging. Sequence acquisition protocols have been refined on multiple occasions within the past decade and, thus, were not uniform.

The anatomic location of each lesion was identified (On-line Table 2 has a full list of brain locations assessed), and the presence of symmetric acute cortical lesions was assessed (involving symmetric gyri or cortical regions). The presence of superficial cortical T2 sparing (involvement of the middle/deep layers of the cortex only) was noted. When serial imaging was available, the evolution of lesion DWI, ADC, and T2 signal was assessed as was the presence of old infarcts and volume loss. Lesion evolution was compared between lesions that demonstrated low ADC versus normal/high ADC values on initial imaging. 


\begin{tabular}{|c|c|c|c|}
\hline Sequence & Intensity & No. of Lesions: Deep & No. of Lesions: Cortical \\
\hline Acute (first week) & & Total: 5 & Total: 36 \\
\hline $\mathrm{Tl}$ (spin-echo) & $\downarrow$ & 0 & 24 \\
\hline T2 (spin-echo) & $\uparrow$ & 5 & 36 \\
\hline T2 sparing of superficial cortex & & & 23 \\
\hline T2 FLAIR & $\uparrow$ & 5 & 36 \\
\hline DWI $(b=1000)$ & $\uparrow$ & 0 & 34 \\
\hline$A D C$ & $\downarrow$ & 0 & 30 \\
\hline SWI & $\downarrow$ & 0 & 0 \\
\hline \multicolumn{4}{|l|}{ Subacute (second-to-fourth weeks) } \\
\hline Prior low ADC & & 0 & 30 \\
\hline Follow-up imaging available & & 0 & 29 \\
\hline $\mathrm{Tl}$ & $\uparrow$ & & 12 \\
\hline T2: black toenail sign & $\downarrow$ & & 21 \\
\hline SWI & $\downarrow$ & & 7 \\
\hline Prior normal/high ADC & & 5 & 6 \\
\hline Follow-up imaging available & & 5 & 6 \\
\hline $\mathrm{T1}$ & $\uparrow$ & 0 & 0 \\
\hline T2: black toenail & $\downarrow$ & 0 & 0 \\
\hline SWI & $\downarrow$ & 0 & 0 \\
\hline \multicolumn{4}{|l|}{ Chronic ( $>3 \mathrm{mo})$} \\
\hline Prior low ADC & & 0 & 30 \\
\hline Follow-up imaging available & & 0 & 19 \\
\hline Volume loss & & & 19 \\
\hline Prior normal/high ADC & & 5 & 6 \\
\hline Follow-up imaging available & & 4 & 4 \\
\hline Volume loss & & 2 & 0 \\
\hline${ }^{1} \mathrm{H}-\mathrm{MRS}$ performed & Doublet at $1.3 \mathrm{ppm}$ & 5 Patients & \\
\hline Long TE (288 ms) & Elevated & 5 Patients & \\
\hline Intermediate TE (144 ms) & Inverted & 5 Patients & \\
\hline Affected white matter & & 5 Patients & \\
\hline Nonaffected white matter & & 3 Patients & \\
\hline
\end{tabular}

Note: $-\downarrow$ indicates hypointense signal; $\uparrow$, hyperintense signal.

\section{RESULTS}

Eight patients who underwent $31 \mathrm{MR}$ imaging studies fulfilled the inclusion criteria (women $=6$, men $=2$; age, mean 26.1 years; range, $18-56$ years at imaging). The demographics, clinical presentations, genetic testing findings, and number of MR imaging studies available for review are reported in Table 1 . All 8 patients had the same genetic pathogenic variant-MT-TL1 $\mathrm{m} .3243 \mathrm{~A}>\mathrm{G}$ (the mutation that is responsible for approximately $80 \%$ of all MELAS cases). Two patients (patients 1 and 2) were siblings. Fifteen of $31 \mathrm{MR}$ imaging studies were performed for assessment of an acute neurologic episode ( 5 for seizures, 9 for stroke-like episodes, 1 for confusion/encephalopathy), 1 study was screening of an asymptomatic individual with an affected sibling and confirmed genetic diagnosis, and 15 studies were followup without new acute neurologic deterioration. Lesion imaging characteristics are outlined in Table 2.

\section{New Lesions}

Across 17 MR imaging studies demonstrating new lesions, 41 new lesions were identified (Table 2). Six studies demonstrated a single new lesion, and 11 studies demonstrated multiple lesions. Fifteen studies were performed for the indication of an acute neurologic episode, and 2 studies that were performed purely for follow-up demonstrated new lesions. Six of 8 patients demonstrated old infarcts with volume loss and multifocal cerebral atrophy, 3 patients had atrophy on the baseline or only available study, and 3 patients developed progressive atrophy during serial imaging.
Three of 5 patients who underwent MR spectroscopy assessment demonstrated elevated lactate doublet peaks in both acutely affected and nonaffected regions of subcortical white matter using single-voxel long-TE ${ }^{1} \mathrm{H}-\mathrm{MRS}$ ( $\mathrm{TE}=288 \mathrm{~ms}$ ), with confirmatory peak inversion to separate lactate from lipid on intermediate $\mathrm{TE}$ acquisitions ( $\mathrm{TE}=144 \mathrm{~ms}$ ).

\section{Anatomic Distribution and Symmetry}

Anatomic distribution results are detailed in On-line Table 3. In summary, the most commonly affected locations were the pericalcarine cortex of the inferior cuneus in the medial occipital lobe-primary visual cortex: Brodmann Area 17 (BA17) $(n=5)$; the middle-third of the postcentral gyrus in the parietal lobe-primary somatosensory cortex: BA3 (homunculus hand/arm region) $(n=5)$; the ventral posterolateral thalamus $(n=4)$; the posterior half of the superior temporal gyrus-primary auditory cortex: BA 41 and $42(n=3)$; and the cerebellar hemisphere posterior lobe folia surface ( $n=3$; two superior, 1 inferior). Four lesions crossed multiple $(>2)$ cortical regions at initial imaging. Five new lesions were deep in location (4 thalamic, 1 red nucleus, and 36 cortical (33 cerebral, 3 cerebellar). Patients 4 and 6 (who had 10 and $8 \mathrm{MR}$ imaging studies, respectively) both demonstrated a caudal-to-rostral evolution in the distribution of cortical lesions with time.

Symmetric new acute lesions were identified in 6 of the 11 studies with multiple new lesions, with symmetry of not just the gyrus involved but to the level of the cortical area/nucleus in all cases (On-line Table 3). 

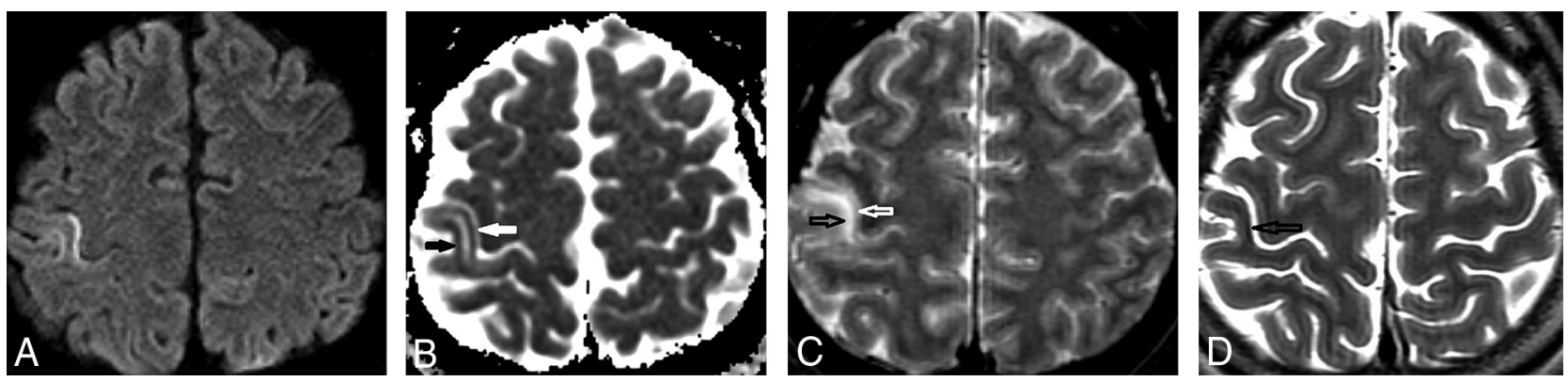

FIG 1. Axial MR imaging shows temporal evolution of an acute cortical lesion in a patient with MELAS presenting with an acute stroke-like episode with left upper limb sensory loss. A, DWI $(b=1000)$ image from the day after symptom onset shows hyperintense intracortical signal in the middle-third of the right postcentral gyrus (hand/arm region of the primary somatosensory cortex). $B, A D C$ image shows corresponding hypointense intracortical signal in keeping with diffusion restriction (white and black arrows). C, T2-weighted spin-echo image shows T2 hyperintensity in the deeper cortical layers and juxtacortical white matter (black arrow), with sparing of the superficial cortex (white arrow). D, Progress T2weighted spin-echo image obtained 3 weeks later shows focal intracortical hypointense signal (black arrow) and mild volume loss, in keeping with pseudolaminar necrosis (black toenail sign).

\section{Lesion Imaging Characteristics}

The 5 deep lesions all demonstrated T2 and FLAIR hyperintensity without diffusion restriction or susceptibility artifacts. Of the 36 cortical lesions, all 36 had T2 and FLAIR hyperintense cortical and subcortical white matter hyperintensity (100\%), 30 had intracortical gyriform diffusion restriction (83.3\%), 23 demonstrated T2 sparing of the most superficial cortical layers (63.9\% of all cortical lesions, $76.7 \%$ of restricting lesions), 24 had acute $\mathrm{T} 1$ hypointensity (66.7\% of all cortical lesions, $80 \%$ of restricting lesions), and none had susceptibility-weighted artifacts at baseline assessment (Table 2). Gadolinium-enhanced T1 imaging was available in only 2 studies with an acute lesion and subacute lesions, respectively, demonstrating adjacent leptomeningeal but no cortical enhancement in the acute lesion and mild intracortical enhancement at the sites of prior diffusion restriction in the subacute lesions.

Of 30 cortical lesions demonstrating acute diffusion restriction, follow-up imaging was available for 29 lesions: Twenty-one lesions evolved to develop T2 hypointense cortical signal on subacute follow-up (black toenail sign, 72.4\%), and 12 lesions developed cortical T1 hyperintensity (41.4\%). Long-term follow-up imaging ( $>3$ months later) was available for 19 of 30 restricting lesions, all of which were associated with focal volume loss (Table 2). Temporal evolution of a typical cortical diffusion-restricting lesion is shown in Fig 1.

\section{DISCUSSION}

\section{Pathophysiology}

The pathophysiology of acute cortical lesions in MELAS is uncertain. Two major theories for their development are the cytopathic theory and the angiopathic theory. ${ }^{10,25}$ The cytopathic theory proposes that defects in oxidative phosphorylation resulting from the mitochondrial mutation cause neuronal and glial cellular dysfunction, potentially resulting in cell death during periods of higher metabolic activity. ${ }^{25,26}$ Known higher baseline metabolic activity in the occipital cortex may partially explain the posterior distribution of lesions in this theory. ${ }^{25,27}$ The angiopathic theory proposes that abnormal mitochondrial function in the arteriolar endothelium results in impaired autoregulation and subsequent ischemia. $^{28}$

\section{Anatomic Distribution of Cortical Lesions}

Preferential distribution of lesions in the posterior cortical regions is well-described in MELAS. ${ }^{1,4,16,20,21,23}$ The particular predominance of pericalcarine visual cortex involvement is a classic feature and explains the frequent clinical presentations with hemianopia or cortical blindness. ${ }^{1,4,10,23}$ The primary visual cortex (BA17) has one of the highest metabolic demands of all cortical regions. ${ }^{27}$ Across the cortical sheet, neuronal density is also highest in the primary visual cortex. ${ }^{29}$ Visual cortex neurons have far more extensive glutaminergic dendritic input than motor cortex neurons, with increased energy demands to maintain ionic homeostasis following excitatory depolarization. ${ }^{27,30}$ In addition, dendrite-rich areas of the cortex are particularly vulnerable to hypoxic damage. ${ }^{31}$ These considerations may support the cytopathic theory of pathogenesis.

The primary somatosensory cortex was the second most common distribution in our study, most often involving the anterior cortex in the middle-third (hand/arm region) of the postcentral gyrus (BA3) (Fig 1). The distribution of mitochondria is greatest in dendrites relative to other cell components, ${ }^{32}$ leaving the dendrite-rich sensory cortex vulnerable to the effects of dysfunctional oxidative phosphorylation. The sensory cortex is known to be particularly vulnerable to hypoxia-induced injury. ${ }^{33}$

Primary motor cortex (BA4) involvement was seen in our study despite the known lower neuronal density, ${ }^{34,35}$ was frequently symmetric, and was restricted to the middle or lateral thirds with relative sparing of the medial third (identical to the somatosensory distribution). The middle and lateral aspects of the motor cortex are in charge of fine movements of the fingers, tongue, and lips, having higher neuronal density and metabolic activity than those of the more medial leg/foot regions. ${ }^{34}$

The highly specific distribution of acute lesions to focal cortical areas of higher neuronal density and metabolic demand would, in our opinion, favor the cytopathic theory of pathogenesis. An additional interesting finding in 2 patients was the evolving caudal-to-rostral lesion distribution across time, beginning in the visual cortex, then involving the parietal cortex, and finally involving the motor cortex and middle frontal gyri in later studies. This caudal-rostral evolution may represent progression in 

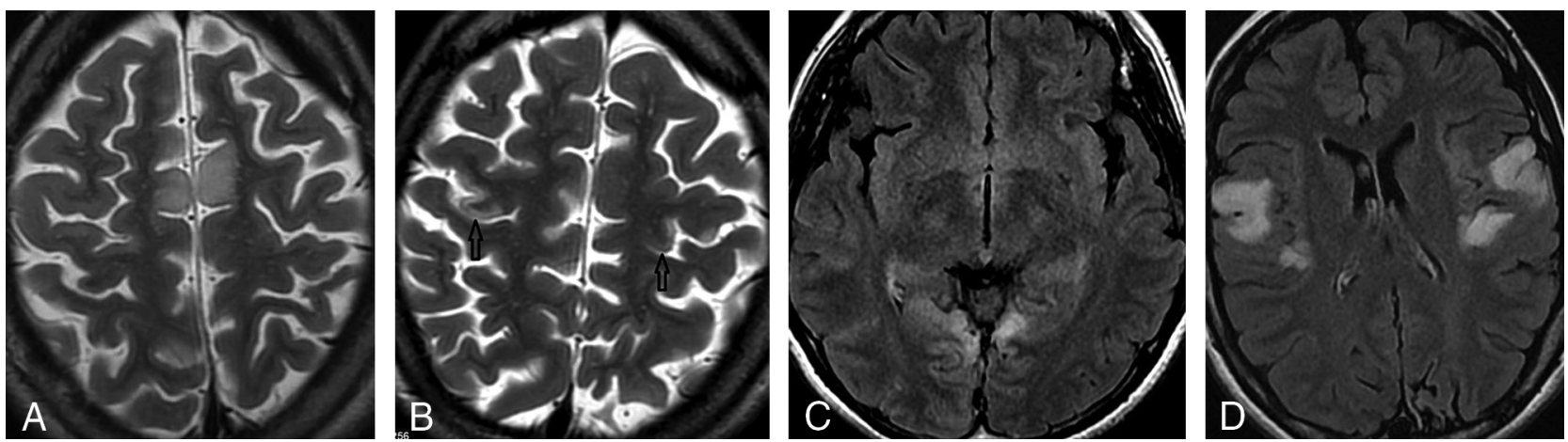

FIG 2. Axial MR imaging shows 4 examples of symmetric cortical involvement by acute lesions in patients with MELAS. A, T2-weighted spinecho image shows symmetric hyperintense signal in the deep cortex and juxtacortical white matter of the bilateral medial frontal gyri, with sparing of the superficial cortex (typical for pseudolaminar involvement). B, T2-weighted spin-echo image shows symmetric hyperintense intracortical signal in the middle-thirds (black arrows) of the bilateral precentral gyri (hand regions of the primary motor cortex), with sparing of the superficial cortex. C, T2-FLAIR image shows symmetric cortical and subcortical hyperintense signal in the pericalcarine cortex of the bilateral medial occipital lobes (primary visual cortex). D, T2-FLAIR image shows symmetric cortical and subcortical hyperintense signal in the posterior halves of the bilateral superior temporal gyri (primary auditory cortex).

the severity of cellular dysfunction with time, which initially manifests in the most vulnerable cortex before affecting less vulnerable regions.

\section{Symmetry}

Symmetric cortical involvement was more common in our study than previously described (one-third of all studies positive for new lesions half of all studies with multiple lesions) and was more specific than lobar or gyral involvement, involving specific cortical regions (eg, the primary visual cortex, hand region of the primary sensory or motor cortices, and the primary auditory cortex) (Fig 2). There was even specificity to the anterior cortex of only the middle-third of the postcentral gyrus (BA3 rather than BA1 or 2) and posterior cortex of the middle-third of the postcentral gyrus (Fig 2B). Symmetric lesions have been previously described involving the precentral gyri in a postmortemproved case ${ }^{19}$ and in the superior temporal gyri in a case of acute cortical deafness. ${ }^{24}$

Many published descriptions ${ }^{2,4,5,10,17}$ state that asymmetric cortical involvement is helpful in making the diagnosis of MELAS. Our results would suggest that highly specific cortical symmetry should also raise the possibility of MELAS. In our opinion, the presence of such specific symmetry also supports the cytopathic theory of pathogenesis.

\section{Cortical Laminar Necrosis and Temporal Evolution}

Our results demonstrated 2 typical patterns of temporal evolution (Table 2). More commonly, lesions had acute diffusion restriction, with subacute cortical laminar necrosis and chronic volume loss. Less commonly, there were reversible lesions that did not restrict acutely or undergo volume loss. The reversible pattern is well-described in early MELAS imaging literature (transient "fleeting" cortical lesions), ${ }^{4-6,20,22}$ but our more common pattern of intracortical necrosis is increasingly recognized ${ }^{10,17-19,23,36}$ and may reflect earlier imaging with enhanced sequence protocols across time. Reversible lesions may represent limited neuronal damage that does not reach the threshold for irreversible cell damage. $^{10,17,21,36}$

Cortical laminar necrosis (more correctly pseudolaminar necrosis) is a histopathologic finding in conditions causing cortical energy depletion such as ischemic stroke, diffuse hypoxic injury, or hypoglycaemia. ${ }^{36-38}$ It likely represents selective intracortical neuronal loss in hypoxic environments, whereas pannecrosis of the mantle may be seen with more severe thrombo-occlusion resulting in full-thickness infarction. ${ }^{39,40}$ Both inherited $\left(\mathrm{MELAS}^{17}\right)$ and acquired (cyanide poisoning ${ }^{41}$ ) mitochondrial conditions are known to cause pseudolaminar necrosis. The typical subacute gyriform intracortical T1 hyperintensity with T2 hypointensity on MR imaging does not represent hemorrhage but rather lipid-laden macrophages. ${ }^{38}$ The laminar nature of the necrosis preferentially spares the subpial superficial cortical layers, ${ }^{17,36,38,42}$ with the greatest involvement of the neuron-rich middle cortical layers (layers III-V). ${ }^{40}$

\section{Superficial Cortical T2 Sparing}

In acute cortical lesions, 23/36 demonstrated T2 sparing of the superficial cortex, and all these lesions had diffusion restriction with subsequent volume loss (Table 2). This pattern of superficial sparing has been previously described in MELAS ${ }^{17,19,36}$ and likely reflects pseudolaminar necrosis with relative superficial-layer sparing (as discussed above). ${ }^{17,38}$

\section{Limitations}

Our study is limited by its retrospective nature, the presence of an asymptomatic patient (though this does allow assessment across differing phenotypes), and variable MR imaging sequence protocols that evolved with time. MR spectroscopy was not performed in all patients. It is also likely that young patients imaged at our center with an acute stroke-like episode underwent followup and genetic testing at other centers and were not identified by our methodology. The sample size is small but has homogeneity of the genotype.

AJNR Am J Neuroradiol 41:167-73 Jan 2020 www.ajnr.org 


\section{CONCLUSIONS}

Acute cortical lesions in MELAS most commonly affect the primary visual, somatosensory, motor, or auditory cortices (BA 17, $3,4,41$, and 42), corresponding to regions of increased neuronal density and metabolic demand. Diffusion restriction with cortical laminar necrosis is common and leads to volume loss. Symmetric lesions occur more frequently than previously described.

Disclosures: Timo Krings—UNRELATED: Consultancy: Stryker, Medtronic, Penumbra; Royalties: Thieme; Stock/Stock Options: Marblehead.

\section{REFERENCES}

1. Yatsuga S, Povalko N, Nishioka J, et al. MELAS: a nationwide prospective cohort study of 96 patients in Japan. Biochim Biophys Acta 2012;1820:619-24 CrossRef Medline

2. El-Hattab AW, Adesina AM, Jones J, et al. MELAS syndrome: clinical manifestations, pathogenesis, and treatment options. $\mathrm{Mol}$ Genet Metab 2015;116:4-12 CrossRef Medline

3. Kraya T, Neumann L, Paelecke-Habermann Y, et al. Cognitive impairment, clinical severity and MRI changes in MELAS syndrome. Mitochondrion 2019;44:53-57 CrossRef Medline

4. Castillo M, Kwock L, Green C. MELAS syndrome: imaging and proton MR spectroscopic findings. AJNR Am J Neuroradiol 1995;16:23339 Medline

5. Valanne L, Ketonen L, Majander A, et al. Neuroradiologic findings in children with mitochondrial disorders. AJNR Am J Neuroradiol 1998;19:369-77 Medline

6. Hirano M, Ricci E, Koenigsberger MR, et al. MELAS: an original case and clinical criteria for diagnosis. Neuromuscul Disord 1992;2:125-35 CrossRef Medline

7. Goto Y, Nonaka I, Horai S. A mutation in the tRNA(Leu)(UUR) gene associated with the MELAS subgroup of mitochondrial encephalomyopathies. Nature 1990;348:651-53 CrossRef Medline

8. Jean-Francois MJ, Lertrit P, Berkovic SF, et al. Heterogeneity in the phenotypic expression of the mutation in the mitochondrial tRNA (Leu) (UUR) gene generally associated with the MELAS subset of mitochondrial encephalomyopathies. Aust N Z J Med 1994;24:18893 CrossRef Medline

9. Grady JP, Pickett SJ, Ng YS, et al. mtDNA heteroplasmy level and copy number indicate disease burden in $\mathrm{m} .3243 \mathrm{~A}>\mathrm{G}$ mitochondrial disease. $E M B O \mathrm{Mol}$ Med 2018;10 CrossRef Medline

10. Ito H, Mori K, Kagami S. Neuroimaging of stroke-like episodes in MELAS. Brain Dev 2011;33:283-88 CrossRef Medline

11. Xu W, Wen J, Sun C, et al. Conventional and diffusional magnetic resonance imaging features of mitochondrial encephalomyopathy, lactic acidosis, and stroke-like episodes in Chinese patients: a study of 40 cases. J Comput Assist Tomogr 2018;42:510-16 CrossRef Medline

12. Sheerin F, Pretorius PM, Briley D, et al. Differential diagnosis of restricted diffusion confined to the cerebral cortex. Clin Radiol 2008;63:1245-53 CrossRef Medline

13. Wang XY, Noguchi K, Takashima S, et al. Serial diffusion-weighted imaging in a patient with MELAS and presumed cytotoxic oedema. Neuroradiology 2003;45:640-43 CrossRef Medline

14. Moller HE, Kurlemann G, Putzler M, et al. Magnetic resonance spectroscopy in patients with MELAS. J Neurol Sci 2005;229-230:131-39 CrossRef Medline

15. Iizuka T, Sakai F, Kan S, et al. Slowly progressive spread of the stroke-like lesions in MELAS. Neurology 2003;61:1238-44 CrossRef Medline

16. Hongo Y, Kaneko J, Suga H, et al. A cluster of disseminated small cortical lesions in MELAS: its distinctive clinical and neuroimaging features. J Neurol 2019;266:1459-72 CrossRef Medline
17. Valanne L, Paetau A, Suomalainen A, et al. Laminar cortical necrosis in MELAS syndrome: MR and neuropathological observations. Neuropediatrics 1996;27:154-60 CrossRef Medline

18. Whitehead MT, Wien M, Lee B, et al. Black toenail sign in MELAS syndrome. Pediatr Neurol 2017;75:61-65 CrossRef Medline

19. Miyahara H, Matsumoto S, Mokuno K, et al. Autopsied case with MERRF/MELAS overlap syndrome accompanied by stroke-like episodes localized to the precentral gyrus. Neuropathology 2019; 39:212-17 CrossRef Medline

20. Sue CM, Crimmins DS, Soo YS, et al. Neuroradiological features of six kindreds with MELAS tRNA(Leu) A2343G point mutation: implications for pathogenesis. J Neurol Neurosurg Psychiatry 1998;65:233-40 CrossRef Medline

21. Cai SS, von Coelln R, Kouo TJ. Migratory stroke-like lesions in a case of adult-onset mitochondrial encephalomyopathy, lactic acidosis, and stroke-like episodes (MELAS) syndrome and a review of imaging findings. Radiol Case Rep 2016;11:425-29 CrossRef Medline

22. Kim IO, Kim JH, Kim WS, et al. Mitochondrial myopathy-encephalopathy-lactic acidosis-and stroke-like episodes (MELAS) syndrome: CT and MR findings in seven children. AJR Am J Roentgenol 1996;166:641-45 CrossRef Medline

23. Bi WL, Baehring JM, Lesser RL. Evolution of brain imaging abnormalities in mitochondrial encephalomyopathy with lactic acidosis and stroke-like episodes. J Neuroophthalmol 2006;26:25156 CrossRef Medline

24. Pittet MP, Idan RB, Kern I, et al. Acute cortical deafness in a child with MELAS syndrome. J Inherit Metab Dis 2016;39:465-66 CrossRef Medline

25. Iizuka T, Sakai F. Pathogenesis of stroke-like episodes in MELAS: analysis of neurovascular cellular mechanisms. Curr Neurovasc Res 2005;2:29-45 CrossRef Medline

26. Molnar MJ, Valikovics A, Molnar S, et al. Cerebral blood flow and glucose metabolism in mitochondrial disorders. Neurology 2000;55:544-48 CrossRef Medline

27. Wong-Riley M. Energy metabolism of the visual system. Eye Brain 2010;2:99-116 CrossRef Medline

28. Ohama E, Ohara S, Ikuta F, et al. Mitochondrial angiopathy in cerebral blood vessels of mitochondrial encephalomyopathy. Acta Neuropathol 1987;74:226-33 CrossRef Medline

29. Turner EC, Young NA, Reed JL, et al. Distributions of cells and neurons across the cortical sheet in Old World Macaques. Brain Behav Evol 2016;88:1-13 CrossRef Medline

30. Wong-Riley MT. Cytochrome oxidase: an endogenous metabolic marker for neuronal activity. Trends Neurosci 1989;12:94-101 CrossRef Medline

31. Hicks SP, Cavanaugh MC, O'Brien ED. Effects of anoxia on the developing cerebral cortex in the rat. Am J Pathol 1962;40:615-35 Medline

32. Santuy A, Turegano-Lopez M, Rodriguez JR, et al. A quantitative study on the distribution of mitochondria in the neuropil of the juvenile rat somatosensory cortex. Cereb Cortex 2018;28:3673-84 CrossRef Medline

33. Martin LJ, Brambrink A, Koehler RC, et al. Primary sensory and forebrain motor systems in the newborn brain are preferentially damaged by hypoxia-ischemia. J Comp Neurol 1997;377:262-85 CrossRef Medline

34. Young NA, Collins CE, Kaas JH. Cell and neuron densities in the primary motor cortex of primates. Front Neural Circuits 2013;7:30 CrossRef Medline

35. Collins CE, Airey DC, Young NA, et al. Neuron densities vary across and within cortical areas in primates. Proc Natl Acad Sci USA 2010;107:15927-32 CrossRef Medline

36. Finsterer J. Laminar cortical necrosis in mitochondrial disorders. Clin Neurol Neurosurg 2009;111:655-58 CrossRef Medline

37. Lee BW, Jin ES, Hwang HS, et al. A case of hypoglycemic brain injuries with cortical laminar necrosis. J Korean Med Sci 2010;25:96165 CrossRef Medline

38. Castillo M, Scatliff JH, Kwock L, et al. Postmortem MR imaging of lobar cerebral infarction with pathologic and in vivo correlation. Radiographics 1996;16:241-50 CrossRef Medline 
39. Kesavadas C, Santhosh K, Thomas B, et al. Signal changes in cortical laminar necrosis-evidence from susceptibility-weighted magnetic resonance imaging. Neuroradiology 2009;51:293-98 CrossRef Medline

40. Ferrer I, Vidal N. Neuropathology of cerebrovascular diseases. Handb Clin Neurol 2017;145:79-114 CrossRef Medline
41. Riudavets MA, Aronica-Pollak P, Troncoso JC. Pseudolaminar necrosis in cyanide intoxication: a neuropathology case report. $\mathrm{Am} \mathrm{J}$ Forensic Med Pathol 2005;26:189-91 Medline

42. Yokoyama T, Hasegawa K, Obama R, et al. MELAS with diffuse degeneration of the cerebral white matter: report of an autopsy case. Neuropathology 2010;30:56-60 CrossRef Medline 